NOTES

\title{
Organosoluble and Light-Colored Fluorinated Polyimides Based on 1,2-Bis(4-amino-2-trifluoromethylphenoxy)benzene and Aromatic Dianhydrides
}

\author{
Chin-Ping YANG,${ }^{\dagger}$ Ruei-Shin ChEn, and Hsun-Ching CHIANG \\ Department of Chemical Engineering, Tatung University, 40 Chungshan North Road, Section 3, Taipei 104, Taiwan
}

(Received September 18, 2002; Accepted May 20, 2003)

KEY WORDS Fluorine-Containing Polyimides / Organosoluble / Color Intensity / Dielectric Property / 1,2-Bis(4-amino-2-trifluoromethylphenoxy)benzene /

Aromatic polyimides are well known as polymer materials of high performance for their excellent thermal stabilities and balanced mechanical and electric properties. ${ }^{1-7}$ Polyimides are mainly used in the aerospace and electronics industries in the form of films and moldings. Optical transparency of polyimide films is special importance in some applications such as flexible solar radiation protectors, ${ }^{8}$ orientation films in liquid crystal display devices, ${ }^{9}$ optical waveguides for communication interconnects, ${ }^{10}$ and optical half-waveplates for planar lightwave circuits. ${ }^{11}$ However, the wholly aromatic polyimides strongly absorb in the visible region of their UV-Vis spectra and are pale yellow or deep reddish yellow because of their highly conjugated aromatic structures and/or the intermolecular chargetransfer complex (CTC) formation; besides, they are difficult to process because of high softening temperatures and limited solubility in commercially available solvents.

Aromatic polyimides possess many useful properties and are increasingly being required by the electronic circuit industry. ${ }^{5,12}$ A low dielectric constant is one of the most attractive properties of polyimide materials for electronic applications. One of the most effective methods to decrease the dielectric constant is to introduce fluorine atoms into polyimide materials. ${ }^{12}$ Fluorination is also known to enhance the solubility and optical transparency of polyimides. ${ }^{13-15}$ Therefore, it is expected that fluorinated polyimides will be widely applied in electro-optical and semiconductor industries.

Recent studies demonstrated that polyimides derived from ether-bridged aromatic diamines with trifluoromethyl $(3 \mathrm{~F})$ groups, such as 1,3- or 1,4-bis(4amino-2-trifluoromethylphenoxy)benzene, are soluble and high temperature polymer materials with low dielectric constant, high optical transparency,

${ }^{\dagger}$ To whom correspondence should be addressed. and low birefringence. ${ }^{16,17}$ In this study, a highpurity $\mathrm{CF}_{3}$-containing diamine, 1,2-bis(4-amino-2trifluoromethylphenoxy)benzene II, was synthesized by modificatory method and subsequently polycondensed with various commercially available aromatic dianhydrides to produce a series of fluorinated polyimides $\mathbf{V}_{\mathbf{a}-\mathbf{f}}$. These polymers were subjected to solubility, thermal, optical, dielectric property measurements and compared to analogous polyimides $\mathbf{V I}_{\mathbf{a}-\mathbf{f}}{ }^{18}$ prepared from a nonfluorinated diamine monomer, 1,2bis(4-aminophenoxy)benzene.

\section{EXPERIMENTAL}

\section{Materials}

Catechol (Acros) and 2-chloro-5-nitrobenzotrifluoride (Acros) were used as received. Pyromellitic dianhydride (PMDA or $\mathbf{I I I}_{\mathbf{a}}$; Lancaster), 3,3',4,4'benzophenonetetracarboxylic dianhydride (BTDA or III ; Acros), diphenylsulfone-3,3',4,4'-tetracarboxylic dianhydride (DSDA or $\mathbf{I I I}_{\mathbf{d}}$; New Japan Chemical Co.) and 4,4'-oxydiphthalic dianhydride (ODPA or III $_{\mathbf{e}}$; Chriskev) were recrystallized from acetic anhydride before use. 3,3',4,4'-Biphenyltetracarboxylic dianhydride (BPDA or $\mathbf{I I I}_{\mathbf{c}}$; Chriskev) and 2,2-bis(3,4dicarboxyphenyl)hexafluoropropane dianhydride (6FDA or III $\mathbf{I}_{\mathbf{f}}$; Chriskev) were purified by sublimation. $N$-Methyl-2-pyrrolidone (NMP; Fluka), $N, N$ dimethylacetamide (DMAc; Fluka), $N, N$-dimethylformamide (DMF; Fluka), and pyridine (Py; Wako) were purified by distillation under reduced pressure over calcium hydride and stored over $4 \AA$ molecular sieves.

\section{Synthesis of Monomer}

1,2-Bis(4-nitro-2-trifluoromethylphenoxy)benzene I. Catechol $(8.26 \mathrm{~g}, 0.075 \mathrm{~mol})$ and 2-chloro-5-nitro- 
benzotrifluoride $(34.28 \mathrm{~g}, \quad 0.152 \mathrm{~mol})$ were first dissolved in $150 \mathrm{~mL}$ of DMF in a $300 \mathrm{~mL}$ flask with stirring. After the mixture was completely dissolved, potassium carbonate $(16.56 \mathrm{~g}, 0.12 \mathrm{~mol})$ was added to it in one portion, and the mixture was heated at $110^{\circ} \mathrm{C}$ for $12 \mathrm{~h}$. The obtained mixture was poured into $600 \mathrm{~mL}$ of methanol/water (volume ratio 1/1) to give a yellow solid, which was collected, washed with water, and dried under vacuum. The crude product was recrystallized from $\mathrm{DMF} /$ methanol to give fine, pale-cream crystals ( $40 \mathrm{~g}, 95 \%)$.

$\mathrm{mp}: \quad 209-210^{\circ} \mathrm{C}$ by $\mathrm{DSC}$ at a scan rate of $10^{\circ} \mathrm{C} \mathrm{min}^{-1}$. Infrared (IR, $\left.\mathrm{KBr}\right): 1530,1350\left(-\mathrm{NO}_{2}\right.$ stretch), 1286, 1180, 1145, $1133 \mathrm{~cm}^{-1}$ (C-F and C-O stretch). Proton nuclear magnetic resonance $\left({ }^{1} \mathrm{H}\right.$ NMR, DMSO- $\left.d_{6}, \delta\right): 8.42\left(\mathrm{dd}, J=9.11,2.68 \mathrm{~Hz}, 2 \mathrm{H}, \mathrm{H}_{\mathrm{b}}\right)$, $8.40\left(\mathrm{~d}, J=2.58 \mathrm{~Hz}, 2 \mathrm{H}, \mathrm{H}_{\mathrm{a}}\right), 7.55\left(\mathrm{~s}, 4 \mathrm{H}, \mathrm{H}_{\mathrm{d}, \mathrm{e}}\right), 7.12$ $\left(\mathrm{d}, J=9.15 \mathrm{~Hz}, 2 \mathrm{H}, \mathrm{H}_{\mathrm{c}}\right.$ ). ${ }^{13} \mathrm{C}$ NMR (DMSO- $d_{6}, \delta$ ): $159.2\left(\mathrm{C}^{4}\right), 144.2\left(\mathrm{C}^{7}\right), 141.8\left(\mathrm{C}^{1}\right), 130.0\left(\mathrm{C}^{6}\right), 128.6$ $\left(\mathrm{C}^{9}\right), 123.6\left(\mathrm{C}^{8}\right), 123.2\left(\mathrm{C}^{2}\right.$, quartet, $\left.{ }^{3} J_{\mathrm{C}-\mathrm{F}}=5 \mathrm{~Hz}\right)$, $121.9\left(\mathrm{C}^{10}\right.$, quartet, $\left.{ }^{1} J_{\mathrm{C}-\mathrm{F}}=271 \mathrm{~Hz}\right), 118.0\left(\mathrm{C}^{3}\right.$, quartet, $\left.{ }^{2} J_{\mathrm{C}-\mathrm{F}}=32 \mathrm{~Hz}\right), 116.8\left(\mathrm{C}^{5}\right)$.

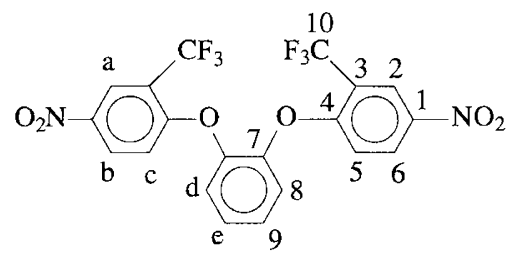

$$
\begin{array}{lllll}
\mathrm{C}_{20} \mathrm{H}_{10} \mathrm{~F}_{6} \mathrm{O}_{6} \mathrm{~N}_{2}(488.30) & \text { Calcd. } & \mathrm{C} 49.20 & \mathrm{H} 2.06 & \text { N } 5.74 \\
& \text { Found } & \mathrm{C} 49.18 & \mathrm{H} 2.07 & \text { N } 5.74
\end{array}
$$

\section{1,2-Bis(4-amino-2-trifluoromethylphenoxy)benzene}

II. To a suspension solution of the purified dinitro compound I $(20 \mathrm{~g}, 0.04 \mathrm{~mol})$ and $10 \% \mathrm{Pd} / \mathrm{C}(0.2 \mathrm{~g})$ in ethanol $(150 \mathrm{~mL})$, hydrazine monohydrate $(7 \mathrm{~mL})$ was added dropwise to the stirred mixture at $70-80^{\circ} \mathrm{C}$ within $30 \mathrm{~min}$. After complete addition, the mixture was heated at reflux temperature for another $2 \mathrm{~h}$. The reaction solution was filtered hot to remove $\mathrm{Pd} / \mathrm{C}$, and the filtrate was poured into water to precipitate white powder that was dried in vacuum at room temperature to give II $(19.2 \mathrm{~g}, 96 \%)$. The crude product was purified by recrystallization from $\mathrm{MeOH} / \mathrm{H}_{2} \mathrm{O}$.

mp: $116-117^{\circ} \mathrm{C}$ by $\operatorname{DSC}\left(10^{\circ} \mathrm{C} \mathrm{min}^{-1}\right)$. IR $(\mathrm{KBr})$ : 3450, 3357, 3327 (N-H stretch), 1265, 1222, 1164, $1123 \mathrm{~cm}^{-1}$ (C-O and C-F stretch). ${ }^{1} \mathrm{H}$ NMR (DMSO$\left.d_{6}, \delta\right): 7.03\left(\mathrm{~m}, 2 \mathrm{H}, \mathrm{H}_{\mathrm{e}}\right), 6.89\left(\mathrm{~d}, 2 \mathrm{H}, \mathrm{H}_{\mathrm{d}}\right), 6.83(\mathrm{~m}$, $\left.2 \mathrm{H}, \mathrm{H}_{\mathrm{a}}\right), 6.74-6.79\left(\mathrm{~m}, 4 \mathrm{H}, \mathrm{H}_{\mathrm{b}, \mathrm{c}}\right), 5.33\left(\mathrm{~s}, 4 \mathrm{H},-\mathrm{NH}_{2}\right)$. ${ }^{13} \mathrm{C}$ NMR (DMSO- $\left.d_{6}, \delta\right): 147.9\left(\mathrm{C}^{7}\right), 145.2\left(\mathrm{C}^{4}\right), 143.7$ $\left(\mathrm{C}^{1}\right), 124.0\left(\mathrm{C}^{9}\right), 123.7\left(\mathrm{C}^{10}\right.$, quartet, $\left.{ }^{1} J_{\mathrm{C}-\mathrm{F}}=271 \mathrm{~Hz}\right)$, $121.1\left(\mathrm{C}^{8}\right), 120.5\left(\mathrm{C}^{3}\right.$, quartet, $\left.{ }^{2} J_{\mathrm{C}-\mathrm{F}}=30 \mathrm{~Hz}\right), 119.1$ $\left(\mathrm{C}^{5}\right), 118.6\left(\mathrm{C}^{6}\right), 111.0\left(\mathrm{C}^{2}\right.$, quartet, $\left.{ }^{3} J_{\mathrm{C}-\mathrm{F}}=5 \mathrm{~Hz}\right)$.

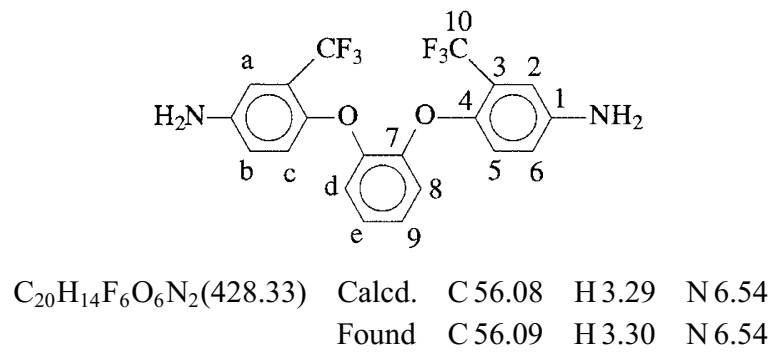

\section{Synthesis of Polyimides}

The general polymerization procedure is illustrated by the following example. Diamine II $(0.428 \mathrm{~g}$, $1 \mathrm{mmol}$ ) was dissolved in $5.7 \mathrm{~mL}$ of dried DMAc in a $50 \mathrm{~mL}$ flask. After the diamine was dissolved completely, $0.218 \mathrm{~g}(1 \mathrm{mmol})$ of PMDA III $_{\mathbf{a}}$ was added to it in one portion. The mixture was stirred at room temperature for $12 \mathrm{~h}$ to form a poly (amic acid) (PAA) solution. PAA solution then was poured into a glass culture dish $(\phi=9 \mathrm{~cm})$, which was placed in an $80^{\circ} \mathrm{C}$ oven for $1 \mathrm{~h}$ to remove the solvent. The semidried PAA film was further dried and imidized by sequential heating at $120^{\circ} \mathrm{C}$ for $10 \mathrm{~min}, 150^{\circ} \mathrm{C}$ for $10 \mathrm{~min}, 180^{\circ} \mathrm{C}$ for $10 \mathrm{~min}, 210^{\circ} \mathrm{C}$ for $10 \mathrm{~min}$, and $250^{\circ} \mathrm{C}$ for $30 \mathrm{~min}$. By being soaked in water, a flexible polyimide film of $\mathbf{V}_{\mathbf{a}}$ was self-stripped off from the glass surface. The inherent viscosity of $\mathbf{V}_{\mathbf{a}}$ in DMAc at a $0.5 \mathrm{~g} \mathrm{dL}^{-1}$ concentration at $30^{\circ} \mathrm{C}$ was $0.76 \mathrm{dL} \mathrm{g}^{-1}$ (Table I).

IR (film): 1781, 1730 (imide $\mathrm{C}=\mathrm{O}$ ), 1380 (C$\mathrm{N}$ stretch), $1103,726 \mathrm{~cm}^{-1}$ (imide ring deformation). ${ }^{1} \mathrm{H}$ NMR (DMSO- $\left.d_{6}, \delta\right): 8.38\left(\mathrm{~s}, 2 \mathrm{H}, \mathrm{H}_{\mathrm{f}}\right), 7.91(\mathrm{~s}, 2 \mathrm{H}$, $\left.\mathrm{H}_{\mathrm{a}}\right), 7.75\left(\mathrm{~d}, J=9.55 \mathrm{~Hz}, 2 \mathrm{H}, \mathrm{H}_{\mathrm{b}}\right), 7.46\left(\mathrm{~s}, 4 \mathrm{H}, \mathrm{H}_{\mathrm{d}, \mathrm{e}}\right)$, $7.15\left(\mathrm{~d}, J=9.0 \mathrm{~Hz}, 2 \mathrm{H}, \mathrm{H}_{\mathrm{c}}\right) .{ }^{13} \mathrm{C}$ NMR (DMSO- $d_{6}, \delta$ ): $165.2\left(\mathrm{C}^{13}\right), 154.3\left(\mathrm{C}^{4}\right), 145.4\left(\mathrm{C}^{7}\right), 137.0\left(\mathrm{C}^{12}\right), 133.1$ $\left(\mathrm{C}^{1}\right), 127.3\left(\mathrm{C}^{11}\right), 126.0\left(\mathrm{C}^{6,9}\right), 122.9\left(\mathrm{C}^{5}\right), 122.8\left(\mathrm{C}^{10}\right.$, quartet, $\left.{ }^{1} J_{\mathrm{C}-\mathrm{F}}=271 \mathrm{~Hz}\right), 118.5\left(\mathrm{C}^{3}\right.$, quartet, ${ }^{2} J_{\mathrm{C}-\mathrm{F}}=$ $32 \mathrm{~Hz}), 117.8\left(\mathrm{C}^{8}\right), 117.1\left(\mathrm{C}^{2}\right)$.

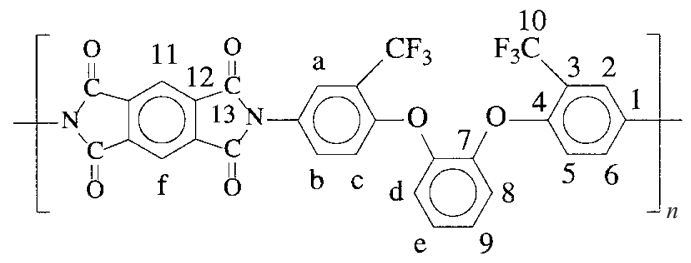

\section{Measurements}

IR spectra were recorded on a Horiba FourierTransform Infrared Spectrometer FT-720. Elemental analyses were run in a PerkinElmer Model $2400 \mathrm{C}, \mathrm{H}$, $\mathrm{N}$ analyzer. ${ }^{1} \mathrm{H}$ and ${ }^{13} \mathrm{C}$ spectra were recorded on a Bruker AV-500 FT-NMR spectrometer. Inherent viscosities were determined at $0.5 \mathrm{~g} \mathrm{dL}^{-1}$ concentration using a Cannon-Fenske viscometer at $30^{\circ} \mathrm{C}$. Thermogravimetry analysis (TGA) was conducted with a TA Instruments TGA 2050. Experiments were carried out 
Table I. Inherent viscosity of poly(amic acid)s and polyimides and elemental analysis of the polyimides

\begin{tabular}{|c|c|c|c|c|c|c|c|c|}
\hline \multicolumn{2}{|c|}{ Poly(amic acid) } & \multicolumn{2}{|c|}{ Polyimide } & Formula & \multicolumn{4}{|c|}{ Elemental analysis $(\%)$} \\
\hline Code & $\begin{array}{c}\eta_{\text {inh }} \\
\left(\mathrm{dL} \mathrm{g}^{-1}\right)^{\mathrm{a}}\end{array}$ & Code & $\begin{array}{c}\eta_{\text {inh }} \\
\left(\mathrm{dL} \mathrm{g}^{-1}\right)^{\mathrm{a}}\end{array}$ & $M_{\mathrm{w}}$ & & $\mathrm{C}$ & $\mathrm{H}$ & $\mathrm{N}$ \\
\hline \multirow[t]{2}{*}{$I V_{a}$} & \multirow[t]{2}{*}{0.80} & \multirow[t]{2}{*}{$\mathbf{V}_{\mathrm{a}}$} & \multirow[t]{2}{*}{0.76} & \multirow{2}{*}{$\begin{array}{c}\left(\mathrm{C}_{30} \mathrm{H}_{12} \mathrm{O}_{6} \mathrm{~N}_{2} \mathrm{~F}_{6}\right)_{n} \\
(610.43)_{n}\end{array}$} & Calcd. & 59.03 & 1.98 & 4.59 \\
\hline & & & & & Found & 59.04 & 2.00 & 4.59 \\
\hline \multirow[t]{2}{*}{$\mathbf{I} \mathbf{V}_{\mathbf{b}}$} & \multirow[t]{2}{*}{0.78} & \multirow[t]{2}{*}{$\mathbf{V}_{\mathbf{b}}$} & \multirow[t]{2}{*}{0.75} & \multirow{2}{*}{$\begin{array}{c}\left(\mathrm{C}_{37} \mathrm{H}_{16} \mathrm{O}_{7} \mathrm{~N}_{2} \mathrm{~F}_{6}\right)_{n} \\
(714.53)_{n}\end{array}$} & Calcd. & 62.20 & 2.26 & 3.92 \\
\hline & & & & & Found & 62.19 & 2.25 & 3.93 \\
\hline \multirow[t]{2}{*}{$\mathbf{I V} \mathbf{V}_{\mathbf{c}}$} & \multirow[t]{2}{*}{0.79} & \multirow[t]{2}{*}{$\mathbf{V}_{\mathbf{c}}$} & \multirow[t]{2}{*}{0.76} & \multirow{2}{*}{$\begin{array}{c}\left(\mathrm{C}_{36} \mathrm{H}_{16} \mathrm{O}_{6} \mathrm{~N}_{2} \mathrm{~F}_{6}\right)_{n} \\
(686.52)_{n}\end{array}$} & Calcd. & 62.98 & 2.35 & 4.08 \\
\hline & & & & & Found & 63.00 & 2.36 & 4.08 \\
\hline \multirow[t]{2}{*}{$\mathbf{I} \mathbf{V}_{\mathbf{d}}$} & \multirow[t]{2}{*}{0.72} & \multirow[t]{2}{*}{$\mathbf{V}_{\mathbf{d}}$} & \multirow[t]{2}{*}{0.68} & \multirow{2}{*}{$\begin{array}{c}\left(\mathrm{C}_{36} \mathrm{H}_{16} \mathrm{O}_{8} \mathrm{~N}_{2} \mathrm{~F}_{6} \mathrm{~S}_{1}\right)_{n} \\
(750.58)_{n}\end{array}$} & Calcd. & 57.61 & 2.15 & 3.73 \\
\hline & & & & & Found & 57.62 & 2.14 & 3.72 \\
\hline \multirow[t]{2}{*}{$\mathbf{I V}$ e } & \multirow[t]{2}{*}{0.75} & \multirow[t]{2}{*}{$\mathbf{V}_{\mathbf{e}}$} & \multirow[t]{2}{*}{0.70} & \multirow{4}{*}{$\begin{array}{c}\left(\mathrm{C}_{36} \mathrm{H}_{16} \mathrm{O}_{7} \mathrm{~N}_{2} \mathrm{~F}_{6}\right)_{n} \\
(702.52)_{n} \\
\left(\mathrm{C}_{39} \mathrm{H}_{16} \mathrm{O}_{6} \mathrm{~N}_{2} \mathrm{~F}_{12}\right)_{n} \\
(836.55)_{n}\end{array}$} & Calcd. & 61.55 & 2.30 & 3.99 \\
\hline & & & & & Found & 61.56 & 2.30 & 3.98 \\
\hline \multirow[t]{2}{*}{$\mathbf{I} \mathbf{V}_{\mathbf{f}}$} & \multirow[t]{2}{*}{0.70} & \multirow[t]{2}{*}{$\mathbf{V}_{\mathbf{f}}$} & \multirow[t]{2}{*}{0.68} & & Calcd. & 56.00 & 1.93 & 3.35 \\
\hline & & & & & Found & 55.98 & 1.92 & 3.36 \\
\hline
\end{tabular}

${ }^{\mathrm{a}}$ Measured at a polymer concentration of $0.5 \mathrm{~g} \mathrm{dL}^{-1}$ in DMAc at $30^{\circ} \mathrm{C}$.

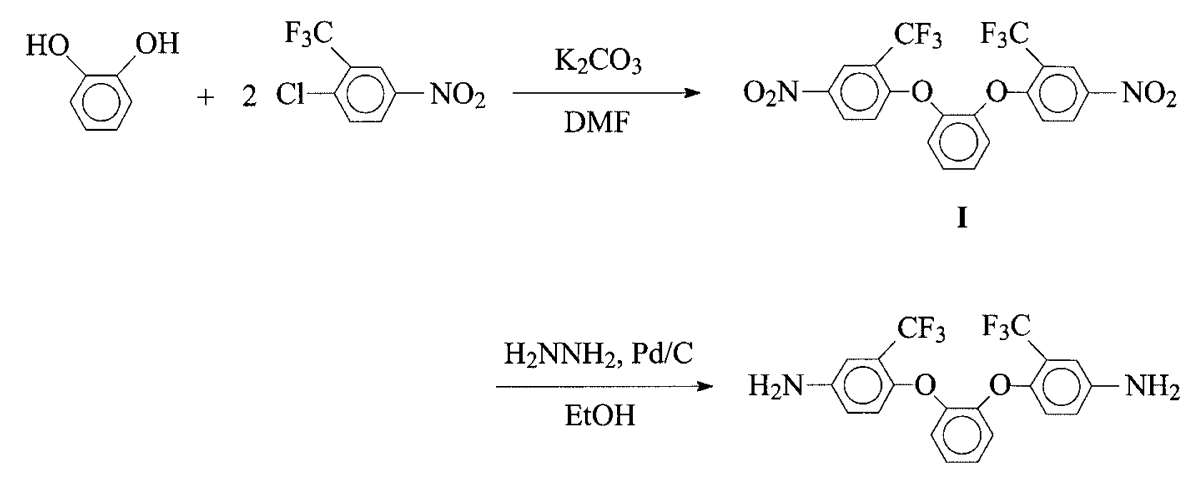

II

Scheme 1. Synthesis of 3F-diamine II.

on 9-11 mg film samples heated in flowing nitrogen or air $\left(100 \mathrm{~cm}^{3} \mathrm{~min}^{-1}\right)$ at a heating rate of $20^{\circ} \mathrm{C} \mathrm{min}^{-1}$. Differential scanning calorimeter (DSC) traces were measured on TA Instruments DSC 2010 at the rate of $15^{\circ} \mathrm{C} \mathrm{min}^{-1}$ in flowing nitrogen $\left(40 \mathrm{~cm}^{3} \mathrm{~min}^{-1}\right)$. Glass transition temperatures were read as the midpoint of the heat capacity jump and were taken from the second heating scan after a quick cooling down from $400{ }^{\circ} \mathrm{C}$. Mechanical properties of the films were measured with an Instron model 1130 tensile tester with a $5 \mathrm{~kg}$ load cell at a crosshead speed of $5 \mathrm{~cm} \mathrm{~min}^{-1}$ on strips approximately $40-50 \mu \mathrm{m}$ thick and $0.5 \mathrm{~cm}$ wide with a $2 \mathrm{~cm}$ gauge length. An average of at least five individual determinations was used. The color intensity of the polymers was evaluated by a Macbeth Color-eye colorimeter. Measurements were performed with films, using an observational angle of $10^{\circ}$ and a CIE (Commission International de 1'Eclairage)-D illuminant. A CIE LAB color difference equation was used. Ultraviolet-visible (UV-vis) spectra of the polymer films were recorded on a Shimadzu UV-1601 UVvis spectrophotometer. The dielectric property of the polymer films was tested by the parallel-plate capacitor method with a Hewlett Packard 4194A dielectric analyzer. Gold electrodes were vacuum-deposited on both surfaces of dried films. Experiments were performed at $25^{\circ} \mathrm{C}$ in a dry chamber.

\section{RESULTS AND DISCUSSION}

\section{Monomer Synthesis}

The $\mathrm{CF}_{3}$-containing diamine II was prepared in two steps according to a well-developed method (Scheme 1). The intermediate dinitro compound I was synthesized from the aromatic nucleophilic substitution of 2-chloro-5-nitrobenzotrifluoride with catechol in the presence of potassium carbonate. Diamine II was readily obtained in high yields by the catalytic reduction of $\mathbf{I}$ with hydrazine hydrate and $\mathrm{Pd} / \mathrm{C}$ catalyst in refluxing ethanol. FT-IR, NMR, and elemental analysis were used to confirm the structures of the intermediate I and the diamine monomer II. In FT-IR spectra, the nitro group of compound I gave two characteristic bands at 1530 and $1350 \mathrm{~cm}^{-1}\left(\mathrm{NO}_{2}\right.$ asymmetric and symmetric stretching). After reduction, the characteristic absorptions of the nitro group disappeared, and the amino 
group showed the pair of $\mathrm{N}-\mathrm{H}$ stretching bands in the region of 3300-3500 $\mathrm{cm}^{-1}$ (As Exp. Part and Figure 1).

The ${ }^{1} \mathrm{H}$ NMR spectra absorption signals of aromatic protons of $\mathbf{I}$ appeared in the region of 7.1-8.5 ppm, and those of II shifted to higher field between $6.7-7.1 \mathrm{ppm}$ as Figure 2. In the ${ }^{1} \mathrm{H}$ NMR spectrum of $\mathbf{I}$, the protons $\mathrm{H}_{\mathrm{b}}$ and $\mathrm{H}_{\mathrm{a}}$ resonated at the farthest downfield region due to the inductive effect of electron withdrawing $-\mathrm{NO}_{2}$ and $-\mathrm{CF}_{3}$ groups; the $\mathrm{H}_{\mathrm{c}}$ ortho-oriented to aromatic ether shifted to the upfield region due to the greater shielding caused by the resonance effect. After reduction, the $\mathrm{H}_{\mathrm{a}}$ of II still resonated at the more downfield region due to the inductive effect of $\mathrm{CF}_{3}$ group, but the $\mathrm{H}_{\mathrm{b}}$ of II shifted to the upfield region due to the electron donating effect of the amino group.

In ${ }^{13} \mathrm{C}$ NMR spectra, all the carbon-13 atoms in $\mathbf{I}$ and

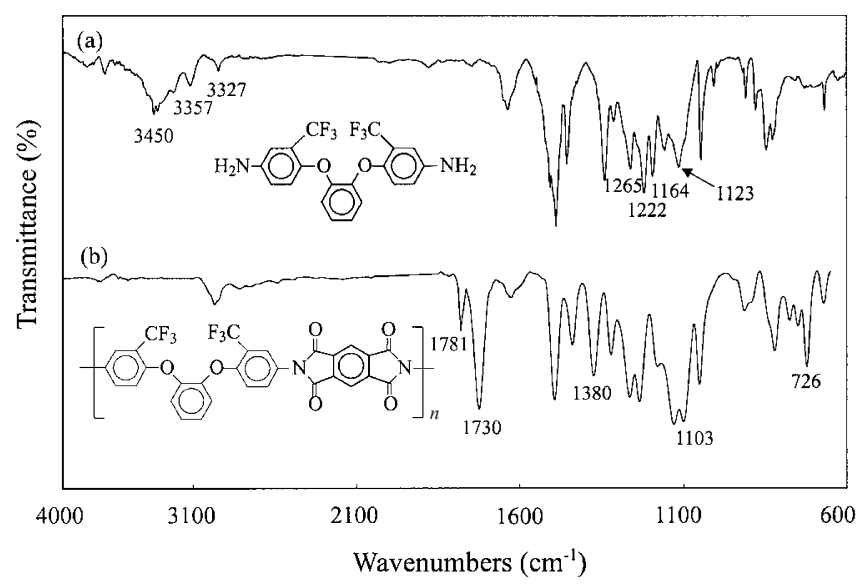

Figure 1. FT-IR spectra of (a) 3F-diamine II and (b) a representative polyimide $\mathbf{V}_{\mathbf{a}}$.
II showed ten main signals, which resonated in the region of 116-160 and 110-148 ppm, respectively. The ${ }^{13} \mathrm{C}$ NMR spectrum of $\mathbf{I}$ shows three quartets because of the heteronuclear ${ }^{13} \mathrm{C}-{ }^{19} \mathrm{~F}$ coupling. The large quartet centered at about $122 \mathrm{ppm}$ was due to the $\mathrm{CF}_{3}$ carbon and the one-bond $\mathrm{C}-\mathrm{F}$ coupling constant was about $271 \mathrm{~Hz}$. The $\mathrm{CF}_{3}$-attached carbon $\left(\mathrm{C}^{3}\right)$ also showed a clear quartet centered at about $118 \mathrm{ppm}$ with a smaller coupling constant of about $32 \mathrm{~Hz}$ due to two-bond $\mathrm{C}_{-}$ $\mathrm{F}$ coupling. Besides, the $\mathrm{C}^{2}$ carbon (ortho to the $\mathrm{CF}_{3}$ group) also had its resonance split by the three fluorines (three-bond coupling). The close quartet had an even smaller coupling constant $(\mathrm{ca} .5 \mathrm{~Hz})$ because the interaction operated over more bonds. Similar splitting patterns (with ${ }^{1} J_{\mathrm{C}-\mathrm{F}}=271 \mathrm{~Hz},{ }^{2} J_{\mathrm{C}-\mathrm{F}}=30 \mathrm{~Hz}$, and ${ }^{3} J_{\mathrm{C}-\mathrm{F}}$ $=5 \mathrm{~Hz}$ ) were also found in the ${ }^{13} \mathrm{C}$ NMR spectrum of II (Figure 2). All the spectroscopic data obtained were in good agreement with the expected structures.

\section{Polymer Synthesis}

All the polymers $\mathbf{V}$ were synthesized from diamine $\mathbf{~ I I}$ and dianhydrides $\mathbf{I I I}_{\mathbf{a}-\mathbf{f}}$, by a conventional two-step procedure ring-opening polyaddition at room temperature to poly(amic acid)s IV, followed by sequential heating to $250^{\circ} \mathrm{C}$ to obtain the corresponding polyimides, as shown in Scheme 2. Figure 3 presents the variation curves of inherent viscosities of the poly(amic acid)s obtained from PMDA with $\mathrm{CF}_{3}-$ containing diamine II or nonfluorinated IY at various times. The reaction of PMDA with fluorinated II proceeded relatively slow and its inherent viscosity
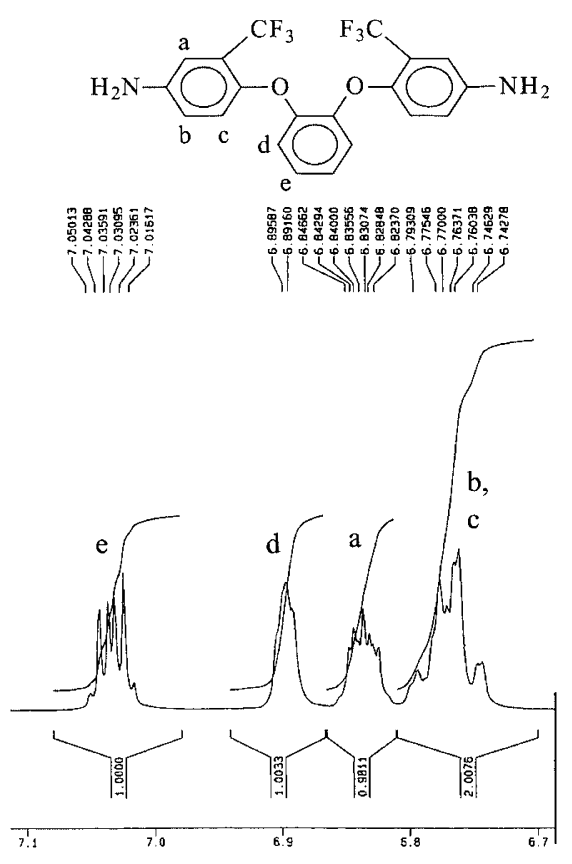

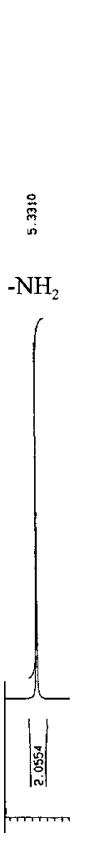

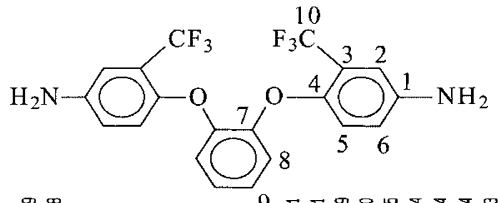

|

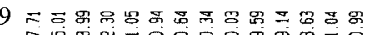

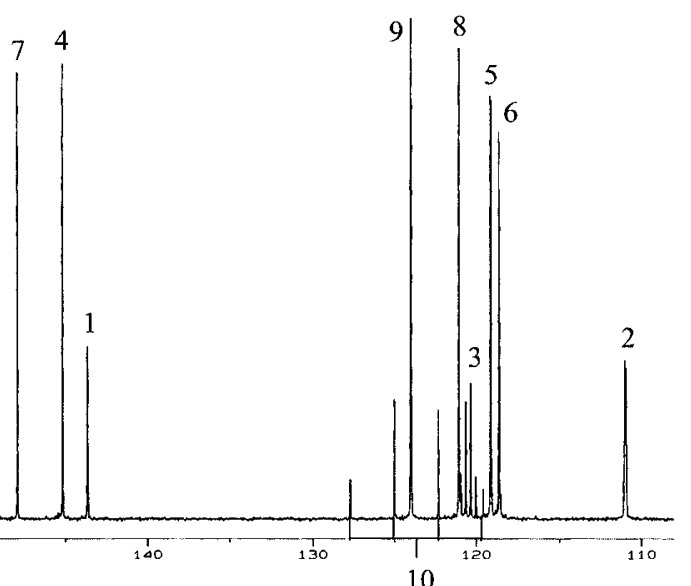

Figure 2. The ${ }^{1} \mathrm{H}$ and ${ }^{13} \mathrm{C}$ NMR spectra of $3 \mathrm{~F}$-diamine II in DMSO- $d_{6}$. 

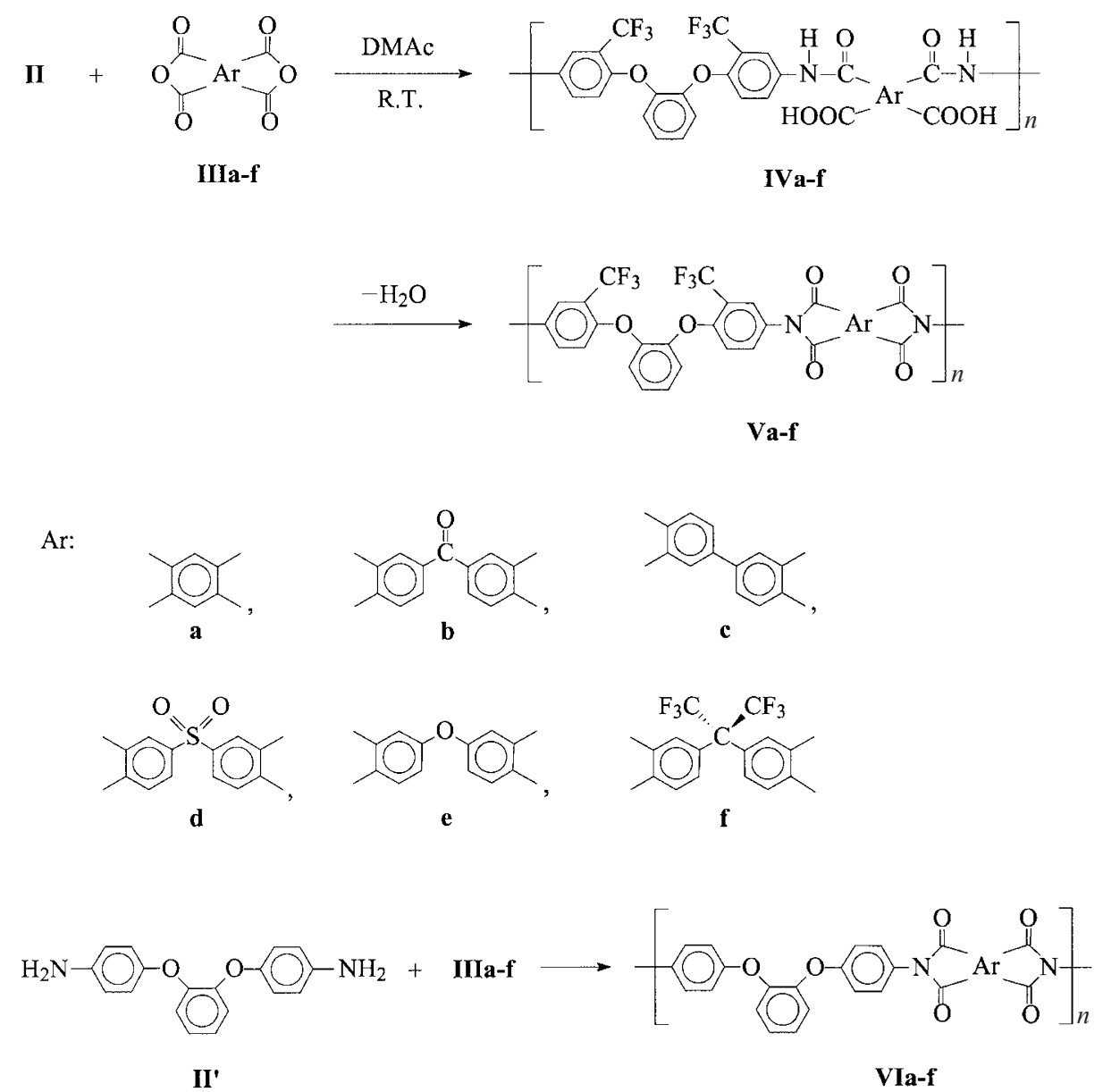

Scheme 2. Synthesis of the polyimides.

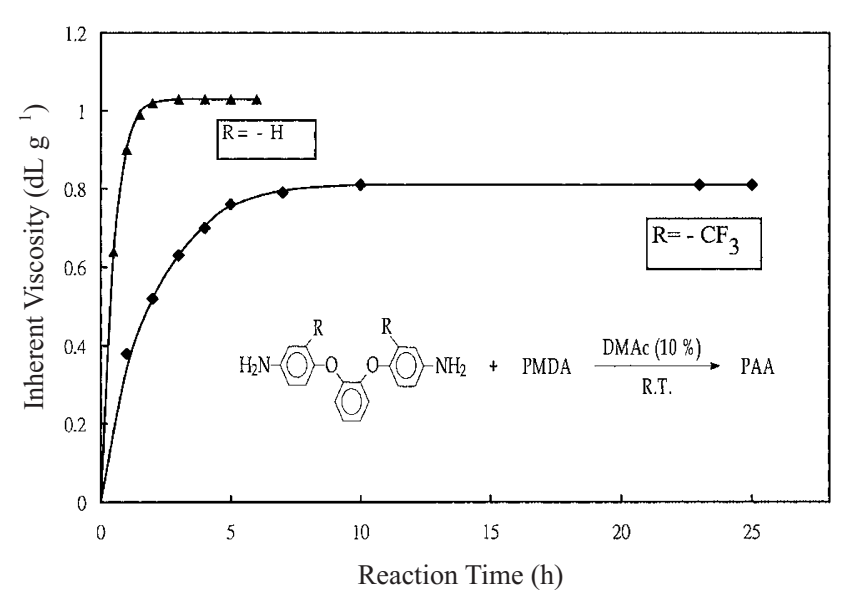

Figure 3. Viscosity change of poly(amic acid)s prepared in DMAc at $10 \%$ solid content at room temperature.

reached $0.76 \mathrm{dL} \mathrm{g}^{-1}$ after $5 \mathrm{~h}$. After this point, inherent viscosity increased slowly; polymerization nearly ceased at $0.8 \mathrm{dL} \mathrm{g}^{-1}$ after $10 \mathrm{~h}$. The reaction of PMDA with $\mathbf{I I}^{\prime}$ proceeded relatively fast and its inherent viscosity increased fast within $50 \mathrm{~min}$; inherent viscosity reached $1.03 \mathrm{dL} \mathrm{g}^{-1}$ after $80 \mathrm{~min}$ and then decreased gradually.

IR spectroscopy allows monitoring of the imide ring formation during thermal curing. The typical set of
FT-IR spectra of polyimide $\mathbf{V}_{\mathbf{a}}$ are shown in Figure 1. As the poly(amic acid) was converted into the polyimide, the characteristic absorption bands of the imide ring were observed near 1781 and 1730 (asymmetrical and symmetrical $\mathrm{C}=\mathrm{O}$ stretching vibration), $1380(\mathrm{C}-$ $\mathrm{N}$ stretching vibration), and 1103 and $726 \mathrm{~cm}^{-1}$ (imide ring deformation), together with some strong absorption bands in the region of $1100-1300 \mathrm{~cm}^{-1}$ due to the $\mathrm{C}-\mathrm{O}$ and $\mathrm{C}-\mathrm{F}$ stretching. The disappearance of amide and carboxyl bands indicates a virtually complete conversion of the poly(amic acid) precursor into polyimide.

In general, structure identification of standard aromatic polyimides by the NMR spectroscopy is difficult due to poor solubility. In this study, polyimides $\mathbf{V}$ had good solubility in organic solvent and could be identified by NMR spectra easily. The typical NMR spectra of soluble polypyromellitimide $\mathbf{V}_{\mathbf{a}}$ are shown in Figure 4. In the ${ }^{1} \mathrm{H} N M R$ spectrum, all the protons resonated in the region of 7.1-8.4 ppm. The protons $\mathrm{H}_{\mathrm{f}}$ on the pyromellitimide unit resonated at the farthest downfield, owing to the inductive effect and resonance. $\mathrm{H}_{\mathrm{a}}$ and $\mathrm{H}_{\mathrm{b}}$ also resonated at lower fields because of close to the electron withdrawing $\mathrm{CF}_{3}$ group and imide ring. The $\mathrm{H}_{\mathrm{c}}$ shifted to higher filed due to the electron donat- 

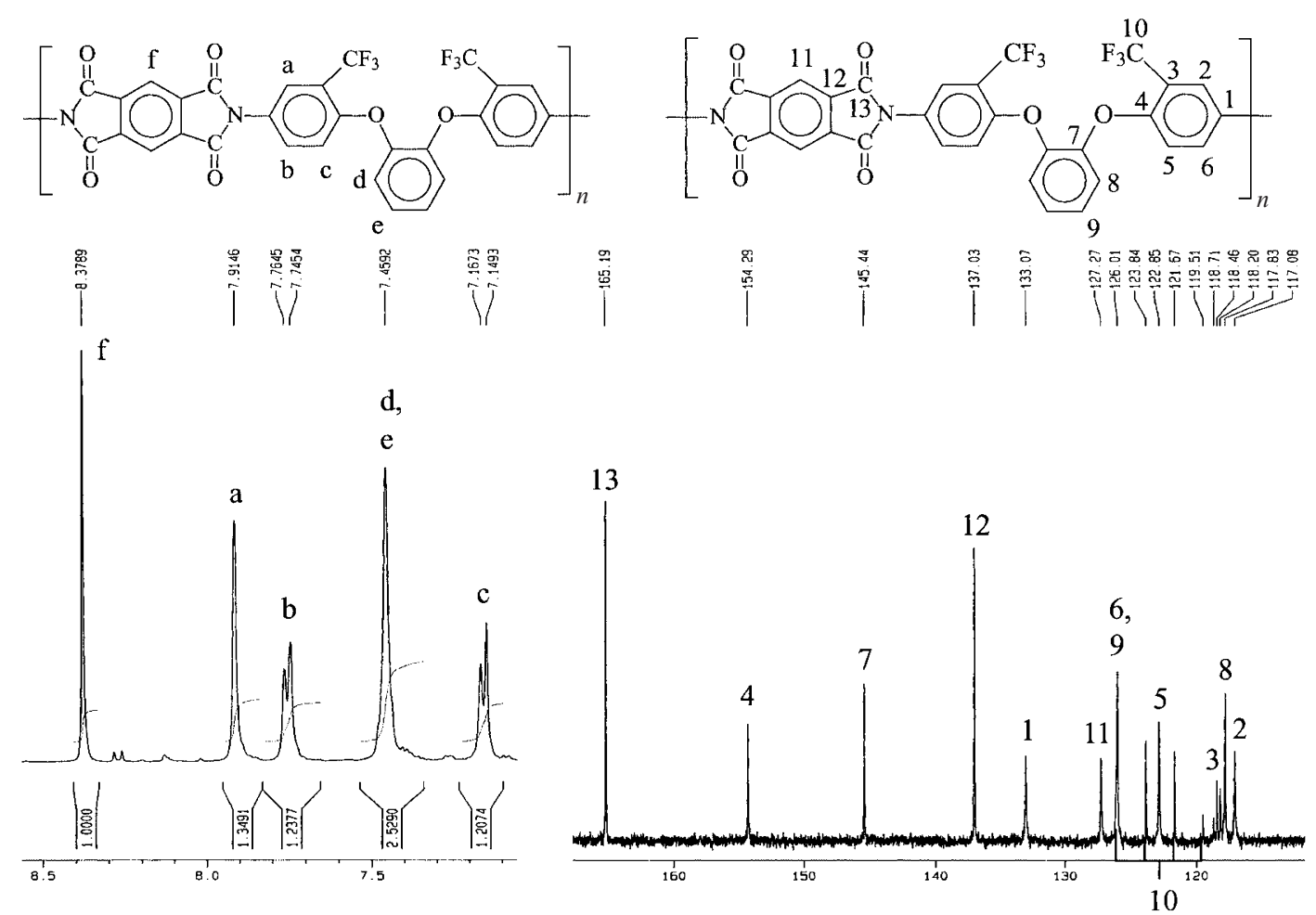

Figure 4. The ${ }^{1} \mathrm{H}$ and ${ }^{13} \mathrm{C}$ NMR spectra of polyimide $\mathbf{V}_{\mathbf{a}}$ in DMSO- $d_{6}$.

ing property of aromatic ether. In ${ }^{13} \mathrm{CNMR}$ spectrum, all the carbon-13 atoms in $\mathbf{V}_{\mathbf{a}}$ showed 13 signals, which were in good agreement with the expected structures. Carbon $\mathrm{C}^{13}$ of the carbonyl group was evidenced in the downfield region. Furthermore, the splitting of the ${ }^{13} \mathrm{C}$ signals caused by couplings between carbon and fluorine also could be observed in the spectrum. The magnitudes of ${ }^{1} J_{\mathrm{C}-\mathrm{F}}$ and ${ }^{2} J_{\mathrm{C}-\mathrm{F}}$ are $271 \mathrm{~Hz}$ and $32 \mathrm{~Hz}$, respectively. The results of elemental analysis of $\mathbf{V}_{\mathbf{a}-\mathbf{f}}$ are listed in Table I. Above-cited results evidenced that series $\mathbf{V}$ had been synthesized successfully.

\section{Properties of Polymer}

The solubility of these polyimides was tested in various organic solvents, and the results are summarized in Table II. Polymers $\mathbf{V}_{\mathbf{a}, \mathbf{c}-\mathbf{f}}$ had excellent solubilities in aprotic polar solvents such as NMP, DMAc, DMF, and DMSO and were also soluble in less polar solvents like pyridine, and dioxane. In general, almost all polypyromellitimides on the basis of various diamines were insoluble in organic solvents. Unlike previous reports, in this study polypyromellitimide $\mathbf{V}_{\mathbf{a}}$ based on special diamine II showed good solubility. However, after heating, $\mathbf{V}_{\mathbf{b}}$ can be dissolved in tested solvents. This might be attributable to the formation of some intermolecular links of the $\mathrm{C}=\mathrm{O}$ group of BTDA during the thermal imidization. On the contrary, $\mathbf{V}_{\mathbf{b}} \mathbf{( C )}$ synthesized via chemical imidization did not possess crosslinks and exhibited better solubility. Compared with polyimides VI, polyimides $\mathbf{V}$ showed better solubility. Poor sol- ubility for the VI series indicates either strong intermolecular interactions or good packing ability. Therefore, the large differences in solubility between the $\mathbf{V}$ and VI series are attributed to the presence of bulky trifluoromethyl group, which inhibited close packing, thereby reducing the interchain interactions to enhance solubility.

The color intensities of the polyimides were elucidated from the yellowness or redness indices observed by a Macbeth color-eye colorimeter. For comparison, the corresponding polyimides VI without the $\mathrm{CF}_{3}$ groups were also prepared and characterized by their color intensity. The color coordinates of these polyimides are given in Table III. The color intensity of polyimides was affected by dianhydride moieties with decreased in the following decreasing order: PMDA $>$ BTDA $>$ DSDA $>$ BPDA $>$ ODPA $>6$ FDA as showed in Figure 5. $\mathbf{V}_{\mathbf{c}-\mathbf{f}}$ displayed lighter color than the others. As compared $\mathbf{V}$ series with $\mathbf{V I}$ series, the results indicate that the $\mathbf{V}$ series showed a lower $b^{*}$ value (a yellowness index) in contrast with the corresponding polyimides VI. The color intensities of the polyimides could also be elucidated from the cutoff wavelength observed in the UV-vis absorption spectra. Figure 6 shows the UV-vis spectra of the polyimide films, and the cutoff wavelengths $\left(\lambda_{0}\right)$ from these spectra are listed in Table III.

Polyimides $\mathbf{V}$ had $\lambda_{0}$ in the range of $365-421 \mathrm{~nm}$. $\mathbf{V}_{\mathbf{c}-\mathbf{f}}$ were lightly colored and exhibited $\lambda_{0}$ lower than $395 \mathrm{~nm}$. In particular, 6FDA and ODPA produced 
Table II. Solubility behavior of the polyimides ${ }^{\mathrm{a}}$

\begin{tabular}{lccccccc}
\hline \multirow{2}{*}{ Polymer } & \multicolumn{7}{c}{ Solvent $^{\mathrm{d}}$} \\
\cline { 2 - 8 } & NMP & DMAc $^{\mathrm{b}}$ & DMF & DMSO & Py & $m$-Cresol & Dioxane \\
\hline $\mathbf{V}_{\mathbf{a}}$ & ++ & ++ & ++ & ++ & ++ & + & + \\
$\mathbf{V}_{\mathbf{b}}$ & + & + & + & + & + & + & $\mathrm{S}$ \\
$\mathbf{V}_{\mathbf{c}}$ & ++ & ++ & ++ & ++ & ++ & + & + \\
$\mathbf{V}_{\mathbf{d}}$ & ++ & ++ & ++ & ++ & ++ & + & + \\
$\mathbf{V}_{\mathbf{e}}$ & ++ & ++ & ++ & ++ & ++ & + & + \\
$\mathbf{V}_{\mathbf{f}}$ & ++ & ++ & ++ & ++ & ++ & ++ & ++ \\
$\mathbf{V}_{\mathbf{b}}(\mathrm{C})^{\mathrm{c}}$ & ++ & ++ & ++ & ++ & ++ & + & + \\
& & & & & & & \\
$\mathbf{V I}_{\mathbf{a}}$ & - & - & - & - & - & - & - \\
$\mathbf{V I}_{\mathbf{b}}$ & $\mathrm{S}$ & - & - & - & - & $\mathrm{S}$ & - \\
$\mathbf{V I}_{\mathbf{c}}$ & ++ & - & - & - & - & + & - \\
$\mathbf{V I}_{\mathbf{d}}$ & - & - & - & - & - & - & - \\
$\mathbf{V I}_{\mathbf{e}}$ & - & - & - & - & - & - & - \\
$\mathbf{V I}_{\mathbf{f}}$ & ++ & ++ & ++ & ++ & ++ & ++ & ++ \\
\hline${ }_{\mathrm{a}}$ & + & & & & & + & + \\
\end{tabular}

${ }^{\text {a }}$ Qualitative solubility was determined with $10 \mathrm{mg}$ of polymer in $1 \mathrm{~mL}$ of solvent: ++ , soluble at room temperature; +, soluble on heating; S, swelling or partially soluble; -, insoluble even on heating. ${ }^{\mathrm{b}}$ The solubility was determined at $10 \%$ solid content. ${ }^{c}$ Polyimides were obtained by the chemical imidization method with NMP as solvent. ${ }^{\mathrm{d}} \mathrm{NMP}: \mathrm{N}$-methyl-2-pyrrolidone; DMAc: $\mathrm{N}, \mathrm{N}$ dimethylacetamide; DMF: $N, N$-dimethylformamide; DMSO: dimethyl sulfoxide; Py: pyridine.

Table III. Color coordinates and cutoff wavelength $\left(\lambda_{0}\right)$ from UV-vis spectra for both $\mathbf{V}$ and VI series polyimides films

\begin{tabular}{|c|c|c|c|c|c|}
\hline \multirow[b]{2}{*}{ Polymer } & \multicolumn{3}{|c|}{ Color Coordinates $^{\mathrm{a}}$} & \multirow[b]{2}{*}{$\lambda_{0}(\mathrm{~nm})^{\mathrm{b}}$} & \multirow{2}{*}{$\begin{array}{c}\text { Film } \\
\text { thickness } \\
(\mu \mathrm{m})\end{array}$} \\
\hline & $b^{*}$ & $a^{*}$ & $\mathrm{~L}^{*}$ & & \\
\hline Paper & 0.97 & -0.43 & 96.20 & - & - \\
\hline $\mathbf{V}_{\mathrm{a}}$ & 67.9 & -10.9 & 91.5 & 421 & 62 \\
\hline $\mathbf{V}_{\mathbf{b}}$ & 52.2 & -3.3 & 93.2 & 405 & 48 \\
\hline $\mathbf{V}_{\mathbf{c}}$ & 22.8 & -7.2 & 95.1 & 394 & 43 \\
\hline $\mathbf{V}_{\mathrm{d}}$ & 24.6 & -9.3 & 94.2 & 395 & 53 \\
\hline $\mathbf{V}_{\mathrm{e}}$ & 14.5 & -5.6 & 95.5 & 369 & 40 \\
\hline $\mathbf{V}_{\mathbf{f}}$ & 10.1 & -3.5 & 95.6 & 365 & 46 \\
\hline $\mathbf{V I}_{\mathbf{a}}$ & 80.5 & -10.1 & 82.2 & 455 & 63 \\
\hline $\mathbf{V I}_{\mathrm{b}}$ & 78.1 & -2.9 & 87.3 & 434 & 50 \\
\hline $\mathbf{V} \mathbf{I}_{\mathrm{c}}$ & 52.0 & -8.6 & 89.3 & 416 & 58 \\
\hline $\mathbf{V} \mathbf{I}_{\mathrm{d}}$ & 52.2 & -3.7 & 84.3 & 415 & 50 \\
\hline $\mathbf{V I} \mathbf{I}_{\mathrm{e}}$ & 31.1 & -6.3 & 91.2 & 386 & 45 \\
\hline $\mathbf{V I}_{\mathbf{f}}$ & 28.4 & -7.1 & 92.6 & 383 & 68 \\
\hline Kapton & 85.1 & -0.3 & 90.1 & 443 & 38 \\
\hline
\end{tabular}

${ }^{\mathrm{a}}$ The color parameters were calculated according to a CIE LAB equation, using paper as a standard. $\mathrm{L}^{*}$ is lightness; 100 means white, while 0 implies black. A positive $\mathrm{a}^{*}$ means red color, while a negative $\mathrm{a}^{*}$ indicated green color. A positive $\mathrm{b}^{*}$ means yellow color, while a negative $\mathrm{b}^{*}$ implies blue color.

${ }^{\mathrm{b}}$ Transparency cut-off wavelength in $\mathrm{nm}$.

fairly transparent and almost colorless polyimide films in contrast to other dianhydrides. Consistent with the results obtained from the colorimeter, all the fluorinated polyimides revealed a shorter $\lambda_{0}$ than their respective nonfluorinated analogues. The light color of the polyimides with the $\mathrm{CF}_{3}$ groups in their diamine

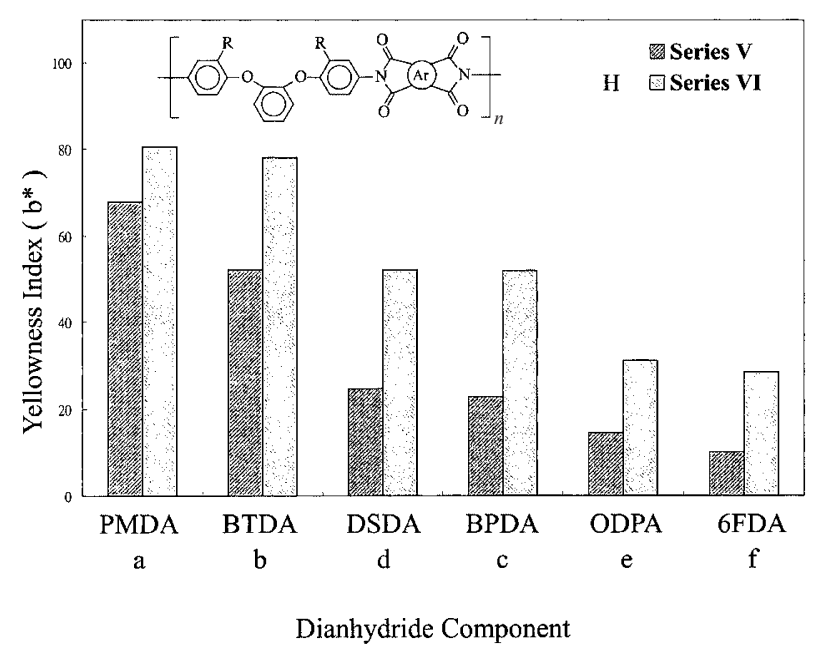

Figure 5. Comparison of the yellowness index ( $b^{*}$ value) between polyimides $\mathbf{V}$ and $\mathbf{V I}$.

moieties could be explained from the decreased intermolecular interactions. The bulky and electronwithdrawing $\mathrm{CF}_{3}$ group in diamine $\mathbf{I I}$ was effective in decreasing CTC formation between polymer chains through steric hindrance and the inductive effect (by decreasing the electron-donating property of diamine moieties). The good optical transparency and lighter color of the ODPA- and 6FDA-derived polyimide films result from the decrease in the intermolecular CTC interaction and electron conjugation by the aromatic ether and the bulky $\mathrm{CF}_{3}$ group.

The tensile properties are summarized in Table IV. These films had strengths at break of $92-123 \mathrm{MPa}$, 


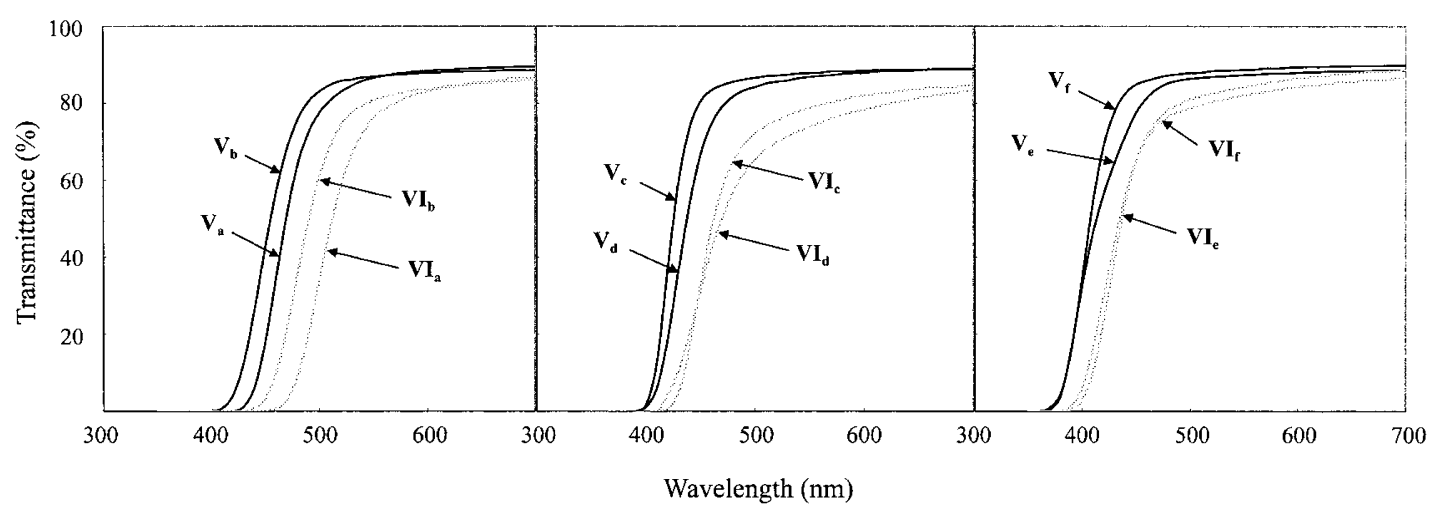

Figure 6. UV-vis spectra of polyimide films.

Table IV. Tensile properties of polyimide films

\begin{tabular}{ccccc}
\hline Polymer & $\begin{array}{c}\text { Strength } \\
\text { at Yield } \\
(\mathrm{MPa})\end{array}$ & $\begin{array}{c}\text { Strength } \\
\text { at Break } \\
(\mathrm{MPa})\end{array}$ & $\begin{array}{c}\text { Elongation } \\
\text { at Break } \\
(\%)\end{array}$ & $\begin{array}{c}\text { Initial } \\
\text { Modulus } \\
(\mathrm{GPa})\end{array}$ \\
\hline $\mathbf{V}_{\mathbf{a}}$ & 101 & 92 & 20 & 2.0 \\
$\mathbf{V}_{\mathbf{b}}$ & - & 123 & 11 & 2.3 \\
$\mathbf{V}_{\mathbf{c}}$ & 123 & 117 & 42 & 2.4 \\
$\mathbf{V}_{\mathbf{d}}$ & - & 108 & 8 & 2.2 \\
$\mathbf{V}_{\mathbf{e}}$ & - & 112 & 17 & 2.2 \\
$\mathbf{V}_{\mathbf{f}}$ & - & 105 & 9 & 2.1 \\
\hline
\end{tabular}

Table V. Thermal behavior data for the polyimides

\begin{tabular}{|c|c|c|c|c|}
\hline \multirow{3}{*}{ Polymer } & \multirow{3}{*}{$\frac{\mathrm{DSC}}{T_{\mathrm{g}}^{\mathrm{a}}\left({ }^{\circ} \mathrm{C}\right)}$} & \multicolumn{3}{|c|}{ TGA } \\
\hline & & \multicolumn{2}{|c|}{ Decomposition Temp. ${ }^{\mathrm{b}}\left({ }^{\circ} \mathrm{C}\right)$} & \multirow{2}{*}{$\begin{array}{c}\text { Char Yield }^{\mathrm{c}} \\
(\mathrm{wt} \%)\end{array}$} \\
\hline & & In Air & In Nitrogen & \\
\hline $\mathbf{V}_{\mathrm{a}}$ & 277 & 582 & 592 & 51 \\
\hline $\mathbf{V}_{\mathbf{b}}$ & 236 & 570 & 585 & 50 \\
\hline $\mathbf{V}_{\mathbf{c}}$ & 249 & 592 & 602 & 59 \\
\hline $\mathbf{V}_{\mathrm{d}}$ & 255 & 547 & 541 & 53 \\
\hline $\mathbf{V}_{\mathrm{e}}$ & 223 & 582 & 590 & 55 \\
\hline $\mathbf{V}_{\mathrm{f}}$ & 247 & 550 & 560 & 52 \\
\hline
\end{tabular}

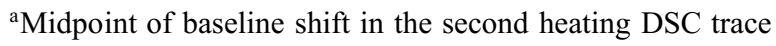
with a heating rate of $15^{\circ} \mathrm{C} \mathrm{min}{ }^{-1}$ under a nitrogen atmosphere. ${ }^{\mathrm{b}} \mathrm{Temperatures}$ at which $10 \%$ weight loss were recorded by TG at a heating rate of $20^{\circ} \mathrm{C} \mathrm{min}^{-1}$. ${ }^{\mathrm{c}}$ Residual weight $\%$ at $800^{\circ} \mathrm{C}$ under a nitrogen atmosphere.

elongations at break of $8-42 \%$, and initial modulus of 2.0-2.4 GPa, respectively. $\mathbf{V}_{\mathbf{a}}$ and $\mathbf{V}_{\mathbf{c}}$ showed a clear yield point on their stress-strain curves (yield strength: 101 and $123 \mathrm{MPa}$ ) and had higher elongation at break, indicating high toughness. Combining rigid dianhydride with tortuous diamine, the capability of polymer backbone to assume a range of conformations while retaining considerable rigidity character may be responsible for this toughness.

The thermal behavior data of all the fluorinated polymers are presented in Table V. DSC experiments were conducted at a heating rate of $15^{\circ} \mathrm{C} \mathrm{min}{ }^{-1}$ in nitrogen. Rapid cooling from $400^{\circ} \mathrm{C}$ to room temperature produced predominantly amorphous samples, so the glass transition temperatures $\left(T_{\mathrm{g}}\right)$ of all the polyimides could be easily read in the subsequent heating DSC traces. The $T_{\mathrm{g}}$ values of polyimides $\mathbf{V}_{\mathbf{a}-\mathbf{f}}$ were in the range of $223-277^{\circ} \mathrm{C}$, depending on the structure of the dianhydride component and decreasing with the increasing flexibility of the polymer backbones. As expected, the polyimide $\mathbf{V}_{\mathbf{a}}$ derived from PMDA exhibited the highest $T_{\mathrm{g}}$ due to the rigid pyromellitimide unit. However, the polyimide $\mathbf{V}_{\mathbf{e}}$ obtained from ODPA showed the lowest $T_{\mathrm{g}}$ of $223^{\circ} \mathrm{C}$. This is reasonable because its dianhydride moiety has a flexible ether linkage.

The thermal stability of the polyimides was evaluated by TGA conducted at a heating rate of $20^{\circ} \mathrm{C} \mathrm{min}^{-1}$. The temperatures of $10 \%$ weight loss $\left(T_{10}\right)$ in nitrogen and air atmospheres were determined from original TGA thermograms and are also tabulated in Table $\mathrm{V}$. The $T_{10}$ values of polyimides $\mathbf{V}_{\mathbf{a}-\mathbf{f}}$ stayed in the range of $541-602^{\circ} \mathrm{C}$ in nitrogen and in the range of $547-592^{\circ} \mathrm{C}$ in air, respectively. They left more than $50 \%$ char yield at $800^{\circ} \mathrm{C}$ in nitrogen. BPDA-derived $\mathbf{V}_{\mathbf{c}}$ had the highest $T_{10}$ and char yield. Polyimide $\mathbf{V}_{\mathbf{d}}$ bearing a sulfonyl group in dianhydride DSDA exhibited lower values than the other polymers. This may be attributed to the weak bonding of C-S bond and easily degradation on the heating process. $\mathbf{V I}_{\mathbf{d}}$ also showed lower thermal stability, as shown in Figure 7.

The measurements of the dielectric constants were performed between gold layers: the polyimide film was dried carefully, and a thin gold layer was vacuumdeposited on both surfaces of the polymer film. This procedure excludes any contact problems. Table VI shows the results. Fluorinated polyimides $\mathbf{V}_{\mathbf{a}-\mathbf{f}}$ had lower dielectric constants $(2.70-3.62$ at $1 \mathrm{MHz})$ than commercial polyimides such as Kapton films and nonfluorinated polyimide $\mathbf{V I}_{\mathbf{a}}$. The decreased dielectric constants might be attributable to the presence of bulky $\mathrm{CF}_{3}$ groups, which resulted in less efficient chain packing and increased free volume. In addition, the strong electronegativity of fluorine resulted in very low polarizability of the $\mathrm{C}-\mathrm{F}$ bonds, thereby decreasing the dielectric constant. Hence, the 6FDA-derived polyimide 


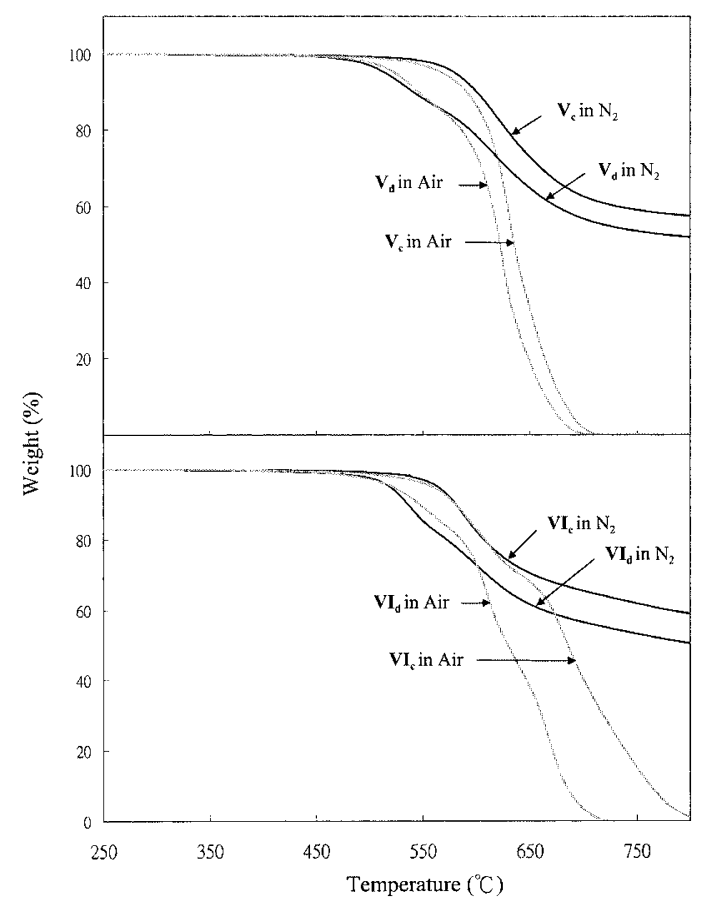

Figure 7. Typical TGA curves of polyimides $\mathbf{V}_{\mathbf{c}, \mathbf{d}}$ and $\mathbf{V I}_{\mathbf{c}, \mathbf{d}}$ with a heating rate of $20^{\circ} \mathrm{C} \mathrm{min}^{-1}$.

Table VI. Moisture absorption and dielectric constants of the polyimides

\begin{tabular}{|c|c|c|c|c|c|}
\hline \multirow{2}{*}{ Polyimide } & \multirow{2}{*}{$\begin{array}{l}\text { Film } \\
\text { thickness } \\
(\mu \mathrm{m})\end{array}$} & \multicolumn{4}{|c|}{ Dielectric Constant } \\
\hline & & $1 \mathrm{kHz}$ & $10 \mathrm{kHz}$ & $1 \mathrm{MHz}$ & $40 \mathrm{MHz}$ \\
\hline $\mathbf{V}_{\mathbf{a}}$ & 85 & 3.64 & 3.63 & 3.62 & 3.60 \\
\hline $\mathbf{V}_{\mathbf{b}}$ & 62 & 3.57 & 3.56 & 3.54 & 3.52 \\
\hline $\mathbf{V}_{\mathbf{c}}$ & 53 & 3.31 & 3.28 & 3.25 & 3.22 \\
\hline $\mathbf{V}_{\mathrm{d}}$ & 55 & 3.53 & 3.51 & 3.47 & 3.45 \\
\hline $\mathbf{V}_{\mathrm{e}}$ & 73 & 3.02 & 2.97 & 2.93 & 2.90 \\
\hline $\mathbf{V}_{\mathbf{f}}$ & 56 & 2.73 & 2.72 & 2.70 & 2.67 \\
\hline $\mathbf{V I}_{\mathbf{a}}$ & 50 & 3.96 & 3.93 & 3.91 & 3.89 \\
\hline Kapton $^{\text {b }}$ & 40 & 3.89 & 3.85 & 3.80 & 3.75 \\
\hline
\end{tabular}

${ }^{\mathrm{a}}$ Data in parentheses are those of the VI series polyimides. ${ }^{\mathrm{b}} \mathrm{A}$ reference polyimide prepared from PMDA and 4,4'-oxydianiline ( $\eta_{\text {inh }}$ of the poly(amic acid) precursor $1.9 \mathrm{dL} \mathrm{g}^{-1}$ ).

$\mathbf{V}_{\mathbf{f}}$ exhibited the lowest dielectric constant than those prepared from the other dianhydrides of polyimides $\mathbf{V}_{\mathbf{a}-\mathbf{e}}$.

\section{CONCLUSIONS}

A high-purity, almost colorless fluorinated diamine II, 1,2-bis(4-amino-2-trifluoromethylphenoxy)benzene, was prepared through nucleophilic substitution reaction of catechol and 2-chloro-5-nitrobenzotrifluoride, followed by catalytic reduction with hydrazine. A series of light-colored and organosoluble polyimides $\mathbf{V}$ have been obtained from the trifluoromethyl-substituted diamine with different aromatic dianhydrides. These polyimides were char- acterized by excellent thermal stability and good mechanical property. They exhibit better solubility, lighter color and lower dielectric constant than corresponding nonfluorinated polyimides.

Acknowledgment. The authors are grateful to the National Science Council of the Republic of China for the support of this work (Grant NSC 91-2216-E-036008).

\section{REFERENCES}

1. C. Feger, M. M. Khojasteh, and M. S. Htoo, Eds., "Advances in Polyimide Science and Technology", Technomic Pub. Co., Lancaster, 1993.

2. M. J. M. Adadie and B. Sillion, "Polyimides and other HighTemperature Polymers", Elsevier Science Publishers B.V., Amsterdam, 1991.

3. K. L. Mittal, Ed., "Polyimide: Synthesis, Characterization, and Application", Vol. I. II, Plemnum Pub. Corp., New York, N.Y., 1984.

4. C. Feger, M. M. Khojasteh, and J. E. McGrath, Eds., "Polyimides, Chemistry and Characterization", Elsevier Science Publishers B.V., Amsterdam, 1989.

5. D. Wilson, H. D. Stenzenberger, and P. M. Hergenrother, Eds., "Polyimides", Black. \& Son, Glasgow, 1990.

6. P. E. Cassidy, "Thermally Stable Polymers", Mercel Dekker, New York, N.Y., 1980.

7. H. H. Yang, "Aromatic High-Strength Fibers", John Wiley \& Sons, Inc., New York, N.Y., 1989.

8. a) B. S. Dupont and N. Bilow, U.S. Patent 4592925 (Jun. 3, 1986).

b) A. L. Landis and A. B. Naselow, U.S. Patent 4645824 (Jul. 24, 1987).

9. a) K. Higashi and Y. Noda, Eur. Patent 0240249 (Oct. 7, 1987).

b) S. Tamai, M. Ohta, S. Kawashima, H. Oikawa, K. Ohkoshi, and A. Yamaguchi, Eur. Patent 0234882 (Sep. 2, 1987).

10. T. Matsuura, S. Ando, S. Sasaki, and F. Yamamoto, Electron. Lett., 29, 2107 (1993).

11. S. Ando, T. Sawada, and Y. Inoue, Electron. Lett., 29, 2143 (1993).

12. M. K. Ghosh and K. L. Mittal, Eds., "Polyimides: Fundamentals and Applications", Marcel Dekker, New York, N.Y., 1996.

13. F. Li, S. Fang, J. J. Ge, P. S. Honigfort, J. C. Chen, F. W. Harris, and S. Z. D. Cheng, Polymer, 40, 4571 (1999).

14. F. Li, J. J. Ge, P. S. Honigfort, S. Fang, J. C. Chen, F. W. Harris, and S. Z. D. Cheng, Polymer, 40, 4987 (1999).

15. C. S. Wang and R. W. Yang, J. Appl. Polym. Sci., 66, 609 (1997).

16. K. Xie, S. Y. Zhang, J. G. Liu, M. H. He, and S. Y. Yang, J. Polym. Sci., Part A: Polym. Chem., 39, 2581 (2001).

17. K. Xie, J. G. Liu, H. W. Zhou, S. Y. Zhang, M. H. He, and S. Y. Yang, Polymer, 42, 7267 (2001).

18. C. P. Yang and J. J. Cherng, J. Polym. Sci., Part A: Polym. Chem., 33, 2209 (1995). 